\title{
PROCENA STANJA I ENERGETSKA SANACIJA VIŠESPRATNE STAMBENE ZGRADE U ULICI STANOJA STANOJEVIĆA U NOVOM SADU
}

\section{ASSESSMENT AND ENERGY RENEWAL OF THE MULTI-STOREY RESIDENTAL BUILDING IN STANOJE STANOJEVIC STREET IN NOVI SAD}

\author{
Biljana Ćulibrk, Fakultet tehničkih nauka, Novi Sad
}

\begin{abstract}
Oblast - GRADJEVINARSTVO
Kratak sadržaj - Rad se sastoji iz dve celine. Prvi deo rada predstavlja teorijsko istraživački deo sa temom „Proizvodi za toplotnu izolaciju zgrada - spoljni kompozitni sistemi za toplotnu izolaciju (ETICS) na bazi mineralne vune"- EUROPIAN STANDARD EN 13500 gde je opisan pojam ETICS sistema, najbitnije osobine, principi primene $i$ način montaže. Takođe, opisan je EN 13500 - evropski standard u kome su utvrđeni zahtevi za fabrički izrađenim ETICS proizvodima koji se isporučuju u kompletu. U drugom delu rada izvršen je vizuelni makroskopski pregled objekta, sa ciljem utvrdjivanja postojećeg stanja za višespratnu stambenu zgradu $u$ Novom Sadu. Za objekat je uradjen proračun energetske efikasnosti. Na osnovu ovog proračuna $i$ vizuelnog pregleda konstrukcije, date su sanacione mere koje povećavaju trajnost objekta, energetsku efikasnost, kao i njegovu usaglašenost sa Pravilnikom o energetskoj efikasnosti.
\end{abstract}

Ključne reči: Procena stanja, energetska efikasnost, sanacione mere, ETICS sistemi

\begin{abstract}
The paper consists of two mutually independent units. The first part of the paper is a theoretical research part with the topic ,Products for thermal insulation of buildings - external thermal insulation composite systems (ETICS) based on mineral wool" - EUROPIAN STANDARD EN 13500 which describes the concept of ETICS system, the most important features, application principles, installation. Also, EN 13500 is described - a European standard which sets out the requirements for factory-made ETICS products that are delivered as a set. In the second part of the paper, a visual macroscopic examination of the object was performed, with the aim of determining the existing condition for a multi-storey residential building in Novi Sad. An energy efficiency calculation was performed for the building. Based on this calculation and visual inspection of the structure, remedial measures are given that increase the durability of the building, energy efficiency, as well as its compliance with the Rulebook on energy efficiency.
\end{abstract}

Keywords:Condition assessment, energetic efficiency, remedial measures, ETICS systems

\section{NAPOMENA:}

Ovaj rad je proistekao iz master rada čiji je mentor bila dr Mirjana Malešev, red. prof.

\section{UVOD}

Rad se sastoji iz dve celine: teorijsko-istraživačkog dela i stručnog dela. U prvom delu rada analiziraju se ETICS sistemi i EUROPIAN STANDARD EN 13500 .

Drugi, stručni deo rada, obuhvata vizuelni pregled konstrukcije i njegovu procenu stanja. Dat je detaljan proračun energetske efikasnosti i priložene su sanacione mere za povećanje trajnosti objekta i energetske efikasnosti.

\section{PROIZVODI ZA TOPLOTNU IZOLACIJU ZGRADA - SPOLJNI KOMPOZITNI SISTEMI ZA TOPLOTNU IZOLACIJU (ETICS) NA BAZI MINERALNE VUNE}

\subsection{Opšte o ETICS sistemima}

ETICS označava spoljni termoizolacioni kompozitni sistem odnosno kompletan skup komponenata, propisno odabranih i proverenih po pitanju kompatibilnosti. Svaki sistem bi trebalo da ima potvrđene tehničke parametre i svojstva u vidu odobrenja, procene ili drugih konkretnih dokumenata. ETICS (Slika 1) se odnosi na nanošenje izolacionog materijala (obično EPS ili mineralna vuna) na spoljnu površinu zida nakon čega sledi malter za lepljenje, malter ili smesa za osnovni premaz i armaturna mreža sa završnim slojem maltera, i po izboru bojenje.

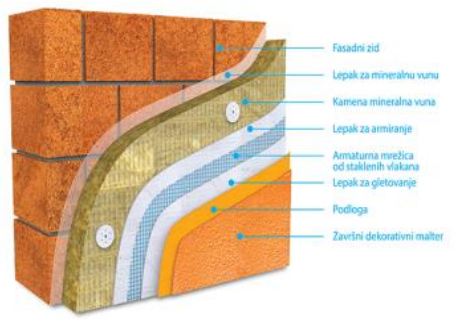

Slika 1. Slojevi ETICS sistema

Trajnost sistema za termoizolaciju zavisi od mnogo faktora [1]. Prvi faktor je praćenje smernica pri nanošenju svake od faza koje su propisane od strane proizvođača. Pored propusta poštovanja osnovnih smernica koje dovode do razaranja sistema, najčešći uzrok prerane degradacije izolacionih sistema jeste nepropisno izrađivanje detalja, koji se rade na osnovu tehničkog projekta $[4,5]$.

Pri montaži obratiti pažnju na:

- Donju ivicu termoizolacionih sistema - prvo pričvrstiti početni profil za zid kojim se postavlja nivo za prvi red ploča (visina sokle mora biti definisana). Neravne podloge mogu dovesti do deformacije fiksnih delova, što 
se izbegava korišćenjem plastične odstojne podloške za bolju nivelaciju i izbegavanje termičkih mostova. Postavljanje ploča kamene vune izvodi se odozdo prema gore sa horizontalnim pomakom od približno pola ploče;

- Dilatacioni spojevi -premošćuju se dilatacionom trakom (poliuretanskom zaptivnom masom);

- Termoizolacija ivica zgrade - izolacione ploče na uglu zgrade trebalo bi da se preklapaju naizmenično, formirajući ugao;

- Okviri prozora i vrata - posebno su izloženi termičkim mostovima, što dovodi do vlažnih zidova na spojevima drvenarije i do pojave algi i gljivica. Oko ivica može doći do nagomilavanja opterećenja. Termoizolacione ploče isečene u L-obliku postaviti na takav način da se ne dodiruju na ivicama prozora ili drugim otvorima na fasadi. Ispod i iznad uglova prozora, s ciljem sprečavanja povećanog naprezanja, trebalo bi postaviti trake armaturne mreže pod uglom od $45^{\circ}$;

- Sokla zgrade - je kritičan deo svake fasade, jer je izložena vodi $\mathrm{i}$ jakom mehaničkom naprezanju. Za izolaciju sokli preporučuju se posebne vrste EPS sa povećanom otpornošću na vodu i ploče od ekstrudiranog polistirena - XPS, koje moraju biti savršeno složene;

- Balkoni i terase - da bi se osigurao kontinuitet izolacije i smanjili termički mostovi najefikasniji metod je staviti izolaciju sa obe strane celom dužinom ploče odnosno izolacioni se materijal stavlja na dno i na strane.

\subsection{Evropski standard EN 13500:2003 (E)}

Ovim evropskim standardom utvrđeni su zahtevi za fabrički izrađe proizvode za spoljne termoizolacione kompozitne sisteme (ETICS) na bazi mineralne vune, koji se isporučuju u kompletu i koriste kao toplotna izolacija zgrada [3]. Standard opisuje karakteristike proizvoda i uključuje postupke za ispitivanje i obeležavanje. Ovaj standard pokriva sisteme sa deklarisanim toplotnim otporom jednakim ili većim od $1 \mathrm{~m}^{2} \times \mathrm{K} / \mathrm{W}$. Treba uzeti u obzir zahteve iz nacionalnih propisa koji se odnose na mehaničku otpornost i stabilnost ETICS-a.

Zahtevi koje standard propisuje su sledeći:

- Toplotna otpornost - vrednost toplotne otpornosti ETICS izračunava se u skladu sa EN ISO 10456 i EN ISO 6946 po formuli $\mathrm{R}=\mathrm{R}_{\mathrm{D}}=\mathrm{d} / \lambda_{\mathrm{D}}$;

- Mehanički otpor i stabilnost sistema - ETICS mora biti stabilan na kombinovana naprezanja kao što su masa, sišuće dejstvo vetra, temperatura, vlaga i skupljanje, kao i od opterećenja pri normalnoj upotrebi; Moraju biti zadovoljeni sledeći zahtevi:

Zatezna čvrstoća veze osnovnog sloja i MV ploče - određena u skladu sa EN 13494. Nijedan rezultat ispitivanja ne sme biti manji od $6 \mathrm{kPa}$;

$>$ Čvrstoća vezivanja lepka na MV ploču za ETICS pričvršćen lepkom- otpornost na čupanje određena se u skladu sa EN 13494. Nijedan rezultat ispitivanja ne sme biti manji od $6 \mathrm{kPa}$;

$>$ Otpornost na izvlačenje ETICS-a fiksiranog mehaničkim pričvršćavanjem - određena u skladu sa EN 13495 bez upotrebe lepka između izolacije i podloge. Projektovani otpor na izvlačenje $X_{d}$ ETICS-a mora biti veći od projektovanog usisanog opterećenja vetra $S_{\mathrm{d}}$;

$>$ Reakcija na požar - određena u skladu sa

EN 13501-1;
MV (mineralna vuna) ploče - moraju biti u skladu sa sa zahtevima navedenim u EN 13162 i zahtevima iz Tabele 1:

\begin{tabular}{|c|c|c|}
\hline \multirow{2}{*}{ Karakteristike } & \multicolumn{2}{|r|}{ Zhtevi } \\
\hline & Vrednosti & Klasa/nivo/granične vrednosti \\
\hline Deklarisana toplotna otpornost & $\mathrm{R}_{\mathrm{D}} \geq 1,00 \mathrm{~m}^{2 *} \mathrm{k} / \mathrm{W}$ & Granične vrednosti \\
\hline $\begin{array}{l}\text { Zatezna čvrtoća upravna na površine: } \\
\text { MV ploče učvršćene lepkom }\end{array}$ & $\geq 80 \mathrm{kPa}$ & TR80 \\
\hline MV ploče učvršćcene šinama & $\geq 15 \mathrm{kPa}$ & TR15 \\
\hline MV ploče učvršećene sidrima & $\geq 7,5 \mathrm{kPa}$ & TR7,5 \\
\hline $\begin{array}{l}\text { MV ploče učvrršećene sidrima kroz } \\
\text { armaturu }\end{array}$ & $>5 \mathrm{kPa}$ & TR5 \\
\hline Dimenzionalna stabilnost & $\leq 1 \%$ & Granične vrednosti \\
\hline Odstupanje od pravouglosti & $\leq 5 \mathrm{~mm} / \mathrm{m}$ & Granične vrednosti \\
\hline Tolerancija ravnosti & $<6 \mathrm{~mm}$ & Granične vrednosti \\
\hline Tolerancija dužine & $\pm 2 \%$ & Granične vrednosti \\
\hline Tolerancija širine & $\pm 1,5 \%$ & Granične vrednosti \\
\hline Tolerancija debljine & $+3 /-1 \mathrm{~mm}$ & T5 \\
\hline Črstoća na pritisak & $\geq 10 \mathrm{kPa}$ & $\operatorname{CS}(10 / \mathrm{Y}) 10$ \\
\hline $\begin{array}{l}\text { Dugotrajno upijanje vode delimičnim } \\
\text { potapanjem }\end{array}$ & $<3 \mathrm{~kg} / \mathrm{m} 2$ & Granične vrednosti \\
\hline
\end{tabular}

Tabela 1. Zahtevi za proizvode za MV ploče

$>$ Zatezna čvrstoća armature - određena u skladu sa EN 13501-1;

$>$ Vodopropustljivost površine sistema određena u skladu sa EN 1062-3. Nijedan rezultat ispitivanja ne sme biti veći od $0,5 \mathrm{~kg} /\left(\mathrm{m}^{2} \times \mathrm{h} 0,5\right)$;

$>$ Otpornost na udar - određena u skladu sa EN 13497. Nijedan rezultat ispitivanja ne sme biti manji od zahtevanog, datog u Tabeli 2:

\begin{tabular}{|c|c|}
\hline Nivo & Uslovi \\
\hline 12 & Nema štete na 2J \\
\hline 110 & Nema štete na 10J \\
\hline
\end{tabular}

Tabela 2. Nivoi otpornosti na udar

$>$ Otpornost na prodiranje - određena u skladu saEN 13498. Nijedan rezultat ispitivanja ne sme biti manji odzahtevanog, datog u Tabeli 3:

\begin{tabular}{|c|c|}
\hline Nivo & Uslovi \\
\hline PE200 & $>200 \mathrm{~N}$ \\
\hline PE500 & $>500 \mathrm{~N}$ \\
\hline
\end{tabular}

Tabela 3. Nivoi otpornosti na prodiranje

Propustljivost vodene pare - određena u skladu sa EN ISO 7783-2. Nijedan rezultat ispitivanja ne sme biti $\operatorname{manji}$ od $40 \mathrm{~g} /\left(\mathrm{m}^{2} \cdot \mathrm{d}\right)$;

$>$ Trajnost i prijanjanje završnog sloja na osnovni material - određuju se u skladu sa prEN ISO 4628-2, prEN ISO 4628-4 i prEN ISO 4628-5 nakon usaglašavanja sa EN 1062-11 (Tabela 4).

\begin{tabular}{|l|l|}
\hline \multicolumn{1}{|c|}{ Karakteristike } & \multicolumn{1}{|c|}{ Uslovi } \\
\hline Stepen mehurića prema prEN ISO 4628-2 & \multicolumn{1}{|c|}{ Nema pukotina ni ljuskanja } \\
\hline Stepen pucanja prema prEN ISO 4628-4 & $\begin{array}{l}\text { Količina pukotina: Ocena 3 (umeren broj } \\
\text { pukotina) } \\
\text { Veličina pukotina: Ocena 2 (maksimalna širina } \\
200 \mu \mathrm{m})\end{array}$ \\
\hline & $\begin{array}{l}\text { Količina ljuštenja :0cena 3( površine sa } \\
\text { ljuskicama s1\%) } \\
\text { Veličina ljuskica: Ocena 2 (veličina ljuskanja } \leq \\
\text { 3mm) }\end{array}$ \\
\hline
\end{tabular}

Tabela 4. Trajnost i prijanjanje završnog sloja na osnovni material

- Metode ispitivanja - Kondicioniranje uzoraka treba uraditi u skladu sa EN 1062-11 za određivanje zatezne čvrstoće veze osnovnog sloja sa termoizolacionim materijalom, vodopusnostljivosti površine, otpornosti na udar, otpornosti na proboj, propustljivost vodene pare, trajnost i prianjanje završnog sloja na osnovni material.

- Testiranje - prikazano u Tabeli 5 


\begin{tabular}{|c|c|c|c|c|}
\hline Naslov & Metoda ispitivanja & $\begin{array}{l}\text { Dimenziie ispitanih } \\
\text { uzoraka }\end{array}$ & $\begin{array}{l}\text { Minimalni broj } \\
\text { merenja da bi se } \\
\text { dobio jedan } \\
\text { rezultat } \\
\end{array}$ & $\begin{array}{l}\text { Posebni } \\
\text { uslovi }\end{array}$ \\
\hline Toplotna otpornost & $\begin{array}{l}\text { EN ISO } 10456 \\
\text { EN ISO } 6946 \\
\end{array}$ & & & \\
\hline $\begin{array}{l}\text { Curstoća na zatezanje veze } \\
\text { osnovnog sloja na MV ploču }\end{array}$ & EN 13494 & $200 \mathrm{~mm} \times 200 \mathrm{~mm}$ & 3 & \\
\hline $\begin{array}{l}\text { Curstóća vezivanja lepka na } \\
\text { MV ploču za ETICS } \\
\text { priť́víścen lepkom - } \\
\text { otpornost na čupaje }\end{array}$ & EN 13494 & $200 \mathrm{~mm} \times 200 \mathrm{~mm}$ & 3 & \\
\hline $\begin{array}{l}\text { Otpornost na izvlačenje } \\
\text { ETrCS-a fiksiranog } \\
\text { mehaníkim } \\
\text { pričvišćcavanjem }\end{array}$ & EN 13495 & $\begin{array}{l}500 \mathrm{~mm} \times 1000 \mathrm{~mm} \times \\
60 \mathrm{~mm}\end{array}$ & 3 & \\
\hline Reakcija na požar & EN 13501-1 & pogledati EN 13501-1 & & \\
\hline Zatezna Črstoça armature & EN 13496 & $\begin{array}{l}\underset{(300 \mathrm{~mm} \times 50 \mathrm{~mm})}{\operatorname{minimum}} \\
\end{array}$ & $\begin{array}{c}7 \text { ispitanih } \\
\text { uzoraka }\end{array}$ & $\begin{array}{c}\text { testiranje pre } \\
\text { i nakon } \\
\text { izlaganja u } \\
\text { agresivnoj } \\
\text { sredini } \\
\end{array}$ \\
\hline $\begin{array}{c}\text { Vodoropusnostljivost } \\
\text { povrsisine sistema }\end{array}$ & EN 1062-3 & Minimum $200 \mathrm{~cm}^{2}$ & 3 & \\
\hline Otpornost na udar & EN 13497 & $\begin{array}{l}500 \mathrm{~mm} \times 1000 \mathrm{~mm} \times \\
60 \mathrm{~mm}\end{array}$ & minimum 5 & \\
\hline Otpornost na proboj & EN 13498 & $200 \mathrm{~mm} \times 200 \mathrm{~mm}$ & minimum 5 & \\
\hline Propust]jivost vodene pare & EN ISO 7783-2 & $\mathrm{D}=90 \mathrm{~mm}$ & 3 & $\begin{array}{c}\text { filter disk } \\
\text { poroznost } 4\end{array}$ \\
\hline $\begin{array}{c}\text { Trajnost i prijianjanje } \\
\text { zavišnog sloja na ossnovni } \\
\text { material }\end{array}$ & $\begin{array}{l}\text { prEN ISO 4628-2 } \\
\text { prrN IOS 4628-4 } \\
\text { prEN ISO 462-5 }\end{array}$ & $200 \mathrm{~mm} \times 200 \mathrm{~mm}$ & 1 & \\
\hline
\end{tabular}

Tabela 5. Metode ispitivanja, uzorci i specijalni uslovi

- Oznake - ETICS - MW - EN 13500 - 2,5 - A2 I2 - PE200 - gde je: R deklarisani termički otpor, Evroklase od A do F - reakcija na požar , li - otpornost na udar, PEi - otpornost na proboj.

- ANEKS A - minimalne učestalosti ispitivanja (Tabela 6)

\begin{tabular}{|c|c|c|c|}
\hline \multirow{3}{*}{ Naslov } & \multicolumn{3}{|c|}{ Minimalne učestalostiispitivanja } \\
\hline & \multirow{2}{*}{ Direktno ispitivanje } & \multicolumn{2}{|c|}{ Indirektno ispitivanje } \\
\hline & & $\overline{\text { Metoda ispitivanja }}$ & Učestalost \\
\hline $\begin{array}{c}\text { CVrstoća vezivanja osnovnog } \\
\text { sloja na MV ploču }\end{array}$ & $\begin{array}{l}1 \text { po mesecu ili } 2 \text { puta po } \\
\text { godini }\end{array}$ & Ručna metoda & 1 po mesecu \\
\hline $\begin{array}{l}\text { Čvistoća vezivanja lepka na MV } \\
\text { ploču za ETICS prǐ̌vršćcen } \\
\text { lepkom }\end{array}$ & $\begin{array}{l}1 \text { po mesecu ili } 2 \text { puta po } \\
\text { godini }\end{array}$ & Ručna metoda & 1 po mesecu \\
\hline $\begin{array}{l}\text { Otpornost na izvlačenje ETICS-a } \\
\text { fiksiranog mehaniökim } \\
\text { pričuřšcavanjem }\end{array}$ & samo početno ispitivanje & & \\
\hline Reakcija na požar & \multicolumn{3}{|c|}{ Poledati narednu tabelu } \\
\hline Zatezna Čvistoća armature & 2 puta po godini & IS0 1887 & 1 po mesecu \\
\hline $\begin{array}{l}\text { Vodoropusnostljivost površine } \\
\text { sistema }\end{array}$ & samo početno ispitivanje & & \\
\hline Otpornost na udar & samo početno ispitivanje & & \\
\hline Otpornost na prodiranje & samo početno ispitivanje & & \\
\hline Propustljivost vodene pare & samo početno ispitivanje & & \\
\hline $\begin{array}{l}\text { Trajnost i prijanjanje zavvšnog } \\
\text { sloja na osnovni material }\end{array}$ & samo početno ispitivanje & & \\
\hline
\end{tabular}

Tabela 6. Minimalne učestalosti isptivanja

\section{PROCENA STANJA ZGRADE}

\subsection{Tehnički opis}

Stambeni objekat spratnosti Su+P+3+Pk (Slika 2), nalazi se u ulici Stanoja Stanojevića u Novom Sadu. Objekat se pruža u pravcu sever-jug. Oblik objekta je kvadratni u osnovi dimenzija 19m x 19m. Objekat ima jedan ulaz sa stepeništem i rampom, vertikalna komunikacija se vrši liftom i unutrašnjim stepeništem. Na spratovima su projektovana po tri stana na etaži $\mathrm{i}$ to na tipskim spratovima I-II-III dva dvoiposobna i jedan trosoban. U prizemlju je projektovan jednosoban, dvoiposoban i jedan trosoban stan. Objekat je prema tipu vertikalnih nosećih elemenata -zidana (masivna) konstrukcija sa vertikalnim serklažima i krutom tavanicom. Obodni zidovi su armiranobetonski do visine suterena, obloženi termoizolacijom, od visine suterena su "sendvič" zidovi zidani punom opekom Sa TI između dva sloja opeka, unutrašnji zidovi su zidani punom opekom na svim etažama, pojedini su obloženi termoizolacijom. Međuspratna konstrukcija iznad suterena je $A B$ puna monolitna ploča koja nosi u dva pravca. Ostale međuspratne konstrukcije su polumontažne, sitnorebraste tipa fert $\mathrm{d}=20 \mathrm{~cm}$ (visina gredica $16 \mathrm{~cm}+4 \mathrm{~cm}$ betonska ploča) ukupne debljine $20 \mathrm{~cm}$. Temeljna ploča je puna $A B$ ploča $\mathrm{d}=40 \mathrm{~cm}$.

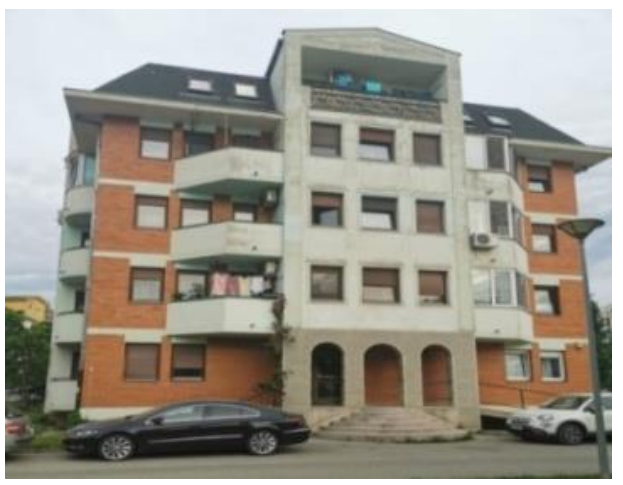

Slika 2. Stambeni objekat

\subsection{Procena stanja objekta}

Prilikom procene stanja konstrukcije obavljen je vizuelni pregled spoljašnjeg i unutrašnjeg dela objekta (suteren i hodnici svih etaža). Proverene su dimenzije dostupnih elemenata konstrukcije i njiho-va usklađenost sa projektom predviđenim dime-nzijama. Pregledom je utvrdjeno da se od glavnog projekta nije odstupalo. Dominantna oštećenja su prsline usled različitog termičkog rada parapetnog i međuprozorskog dela zida javljaju se između svih prozora na sve četiri faside (Slika 3). Od ostalih oštećenja javljaju se mehanička oštećenja (u vidu odlamanja ivica $\mathrm{i}$ rupa), prsline usled promene geometrije i prsline usled isušivanja. Na prilaznoj rampi uočeni su defekti u vidu segregacije.

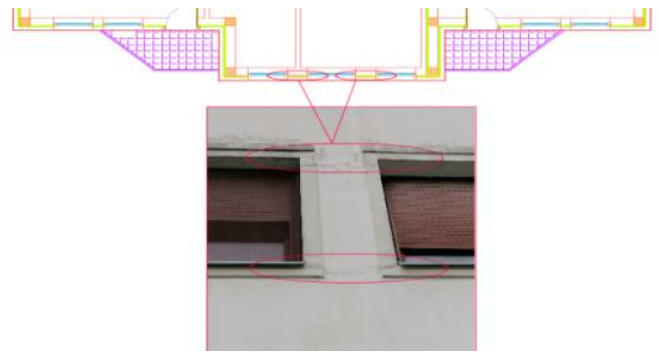

Slika 3. Prsline usled različitog termičkog rada

\subsection{Zaključak}

Sva registrovana oštećenja ne utiču na nosivost, stabilnost i funkcionalnost konstrukcije. Trajnost objekta je smanjena na pojedinim elementima. Pukotine treba sanirati tehnikom zasecanja i zapunjavanja. Na mestima gde je vidljiva armatura potrebno je izvršiti reprofilaciju i premazivanje armature antikorozionim premazima. Prsline i sitne pukotine na objektu potrebno je sanirati popunjavanjem sa zaptivnom masom bez prethodnog zasecanja.

\section{ELABORAT ENERGETSKE EFIKASNOSTI}

\subsection{Gradjevinska fizika}

Pri proračunu energetske efikasnosti urađen je kompletan proračun prolaza toplote kroz građevinske elemente koji čine termički omotač zgrade, proračun difuzije vodene pare, proračun gubitaka i dobitaka toplote, i na kraju proračun godišnje potrebne finalne energije za grejanje. Ovim proračunom je zaključeno da je postojeći objekat trenutno energetskog razreda $\mathrm{D}$ i da ne zadovoljava energetske zahteve za postojeće objekte prema Pravilniku o energetskoj efikasnosti zgrada. U Tabeli 7 dat je pregled 
koeficijenata prolaza toplote kroz termički omotač objekta.

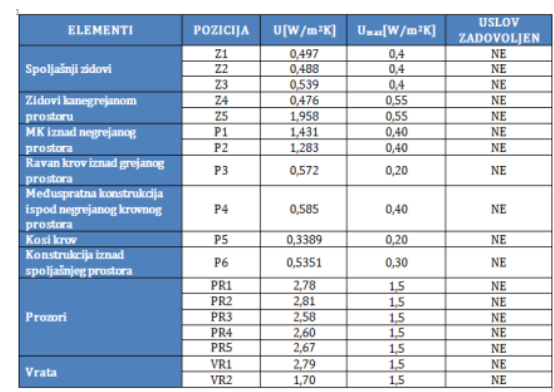

Tabela 7. Koeficijent prolaza toplote

$\mathrm{Na}$ Slici 4 prikazan je dijagram potrebne energije u kWh za grejanje po mesecima. Ukupna godišnja potrebna energija za grejanje je $85.644 \mathrm{kWh} / \mathrm{a}$, dok je specifična potrebna godišnja energija $81,22 \mathrm{kWh} / \mathrm{m}^{2} \mathrm{a}$.

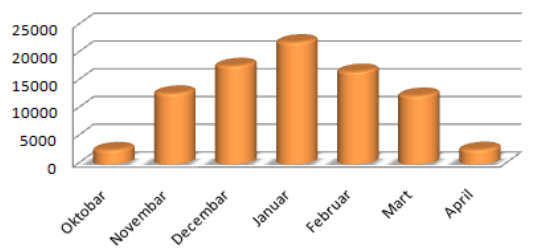

Slika 4. Dijagram potrebne energije $u \mathrm{kWh}$ za grejanje po mesecima

\section{MERE ZA UNAPREĐENJE ENERGETSKE EFIKASNOSTI}

U cilju poboljšanja energetskih potreba i svojstava zgrade predvi]ena je sledeća sanacija pojedinih spoljašnjih zidova, delova međuspratnih konstrukcija i kosog krova u potkrovlju zgrade. Za sanaciju spoljašnjih zidova je predložena ETICS fasada sa mineralnom kamenom vunom [3]. Za termičku izolaciju međuspratne konstrukcije iznad i ispod negrejanih prostora predloženo je postavljanje ekspandiranog polistirena. U potkrovlju na poziciji kosog krova dodaje se kamena vuna kao dodatak termoizolaciji, preko koje se postavljaju gipsane ploče. Debljina sloja kamene vune, odsnosno ekspandiranog polistirena, određena je iz uslova zadovoljenja maksimalnog dozvoljenog koeficijenta prolaza toplote.

Za potrebe proračuna ETICS sistema korišćene su tehničke karakteristike proizvođača "ROCKWOOL" [6]. Za sve ostale materijale, tehničke karakteristike su uzete iz Pravilnika o energetskoj efikasnosti zgrada [1]. U Tabeli 8 dat je pregled koeficijenata prolaza toplote kroz termički omotač objekta posle energetske sanacije.

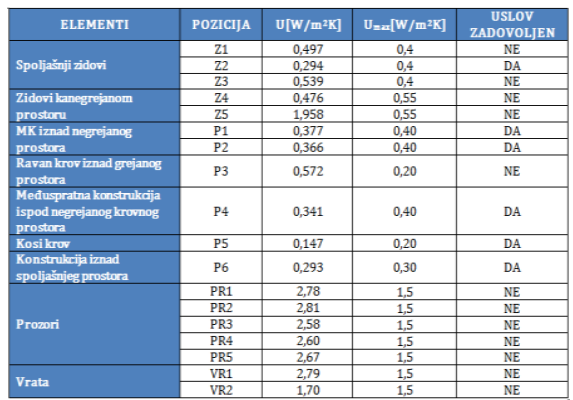

Tabela 8. Koeficijent prolaza toplote
$\mathrm{Na}$ slici 4 prikazan je dijagram potrebne energije u $\mathrm{kWh}$ za grejanje po mesecima. Ukupna godišnja potrebna energija za grejanje je $73613 \mathrm{kWh} / \mathrm{a}$, dok je specifična potrebna godišnja energija $69,81 \mathrm{kWh} / \mathrm{m}^{2} \mathrm{a}$.

$\mathrm{Na}$ slici 7 prikazan je dijagram potrebne energije $\mathrm{u} \mathrm{kWh}$ za grejanje po mesecima nakon energetske sanacije.

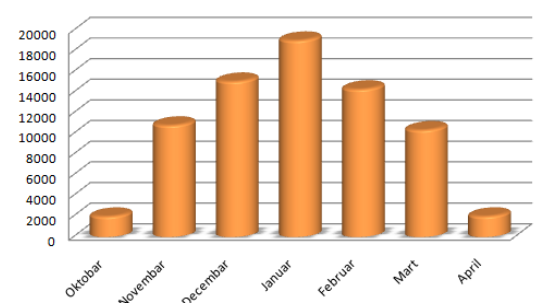

Slika 7. Dijagram potrebne energije u $\mathrm{kWh}$ za grejanje po mesecima nakon izvršene sanacije

Nakon uvodjenja predloženih mera za termičku sanaciju i ponovnog proračuna energetske efikasnosti, potreba za energijom na godišnjem nivou sa značajno smanjila. Energetski razred se popravio i sada objekat pripada $\mathrm{C}$ razredu. Objekat sada zadovoljava uslove po pitanju energetske efikasnosti $u$ skladu sa Pravilnikom o energetskoj efikasnosti (Sl. glasnik RS br.061/2011).

\section{LITERATURA}

[1] Inženjerska komora Srbije: Pravilnik o energetskoj efikasnosti zgrada, "Sl.glasnik RS", br. 61/2011, Beograd [2] Inženjerska komora Srbije: Pravilnik o tehničkim zahtevima bezbednosti od požara spoljnih zidova zgrada, "Sl.glasnik RS", br. 59/2016, 36/2017 i 6/2019 Beograd

[3] EUROPEAN STANDARD EN 13500 - Thermal insulation products for buildings - External thermal insulation composite systems (ETICS) based on mineral wool - Specification

[4] Malešev M., Radonjanin V.: Trajnost i procena stanja betonskih konstrukcija, Skripta sa predavanja, Fakultet tehničkih nauka, Novi Sad

[5] Radonjanin V., Malešev M.: Sanacija betonskih konstrukcija, Skripta sa predavanja, Fakultet tehničkih nauka, Novi Sad

[6] Rešenja i proizvodi ROCKWOOL: www.rockwool.rs

[7] Glavni arhitektonski projekat broj E-38/96 izrađen od ARCHADIA sapo DOO iz feruara 1996. Godine, u Novom Sadu.

\section{Kratka biografija:}

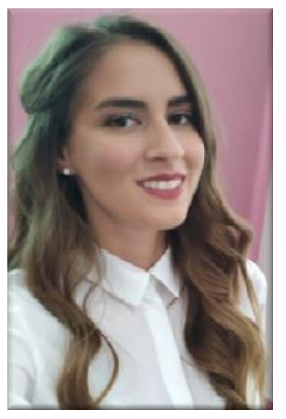

Biljana Ćulibrk rodjena je u Novom Sadu, 1994. godine. Osnovne akademske studije završila je na fakultetu tehničkih nauka 2018. godine, iz oblasti gradjevinarstvo konstruktivni smer. Diplomski rad radila je iz predmeta Tehnologija betona. Master akadamske studije smer-konstrukcije upisala je iste godine. Master rad iz oblasti Sanacija betonskih konstrukcija uradila je i odbranila u 2020. godini. 